\title{
Empirical Data on High Flow Velocity Coolants in Copper Tubing and the Effects on the Coolant's Electrical Resistivity
}

\author{
J.J. Hahne, H-P Liu, C.S. Hearn, E. Schroeder, and J.O’Rarden \\ Center for Electromechanics \\ The University of Texas at Austin \\ Austin, Texas USA
}

\begin{abstract}
The electrical power generation industry has developed a set of guidelines and operating parameters for coolant fluids exposed to high voltage. These guidelines are very system-specific and limited to the operating range of standard utility power generation industries. There is a growing interest today in high energy density pulsed-power generation as well as "power on demand" energy storage devices such as flywheel battery systems. The University of Texas at Austin Center for Electromechanics (UT-CEM) is a leader in the development and prototype testing of such energy storage devices.
\end{abstract}

This paper describes a coolant flow test apparatus at UT-CEM that was used to obtain empirical data for coolant flow in copper tubing. Different test coolant fluids were run though a mock electrical coil with real time fluid parameters monitored and recorded for later analysis. This system recorded and stored fluid flow rate, fluid temperature, fluid $\mathrm{pH}$ level, fluid electrical conductivity, and several system pressures around the fluid circuit. This testing provides an expanded data base and additional guidelines for coolant system performance in high energy density power generators.

Keywords-high flow velocity, coolant, copper tubing, conductivity

\section{INTRODUCTION}

The University of Texas at Austin Center for Electromechanics at (UT-CEM) is a world leader in the development and testing of prototype rotating energy storage devices. Advancements in other technologies such as carbongraphite composites and magnetic bearings have enabled designers to push for more compact rotating machine concepts with an increase in power density. The more aggressive power density makes thermal management within these machines very crucial and these compact energy storage devices force the coolant system and coolant passages to be more compact also. Copper is the coolant passage tubing material of choice in many of these systems. Copper has superior thermal conductivity over other tubing such as steel or stainless steel and in general, these coolant systems are operated at pressure levels that are well within the safe operating pressure ranges for conventional commercial grade copper tubing. The copper coolant passages are kept as small as possible to minimize the impact on machine mass and where current carrying

This research was sponsored by the U.S. Army Research Laboratory through Lockheed-Martin Missile and Fire Control under contract number 4300050944. conductors are present; the coolant passages are kept small to maximize the conductor cross section. To optimize the cooling performance, the coolant passages are immediately adjacent to the conductors or in some designs the coolant passages may be within the conductor cross section itself. The conductor's joule heating temperature increase is the inverse squared function of the conductor cross section so small changes in cross section have significant impact on conductor heating. The machine designer must also trade-off the number of coolant passages to get the best over all system cooling. Adding more coolant passages helps remove more heat, but more coolant passages may reduce the conductor cross section and thus increase the temperature rise and thermal energy to be removed by the coolant system. The conclusion is for the designer to have as few of coolant passages as possible and make the as small as possible and still provide proper thermal management. To maintain turbulent fluid flow in the smaller coolant passages, the coolant flow velocity must increase. UT-CEM was interested in investigating a coolant system with flow velocities of up to $4.6 \mathrm{~m} / \mathrm{s}(15 \mathrm{ft} / \mathrm{s})$ in small diameter $0.31 \mathrm{~cm} \mathrm{x} 0.165 \mathrm{~cm}$ (0.125 in. OD x 0.065 in. ID) copper tubing.

To further complicate the issue, some machine designs have copper coolant passages that are "electrically hot" with several kilovolts of potential to ground. To maintain electrical isolation to ground, the coolant must be non-conductive to prevent leakage currents to ground. Two coolant fluids of choice are deionized (DI) water or a fluorinated liquid. The utility power industry has operated generators for many years with copper coolant passages and DI water as the coolant fluid. These generators also operate with several kilovolts to ground with no adverse current leakage. The utility industry has studied extensively the copper wear rates and the effect on fluid conductivity. The utility industry operates coolant systems at a maximum flow velocity of 1.52 to $1.82 \mathrm{~m} / \mathrm{s}$ (5 to $6 \mathrm{ft} / \mathrm{s}$ ) to minimize copper wear and prolong the copper coolant passages useful life [1].

\section{COPPER TUBING WEAR PARAMETERS}

The copper tubing wear is driven by two different phenomena; physical erosion of the copper tubing due to fluid flow, and chemical corrosion due to chemical reactions between the fluid and copper tubing. The utility industry's 
guideline for flow velocities up to 1.52 to $1.82 \mathrm{~m} / \mathrm{s}$ (5 to $6 \mathrm{ft} / \mathrm{s}$ ) allow copper coolant passage systems to operate for many years with reliable and safe performance. Controlling the copper tubing wear due to chemical corrosion is not as simple.

The rate of copper corrosion is driven by several variables: dissolved oxygen content, $\mathrm{pH}$, and temperature [2]. The corrosion process [3] begins as oxygen $\left(\mathrm{O}_{2}\right)$ and carbon dioxide $\left(\mathrm{CO}_{2}\right)$ present in the water. The oxygen forms a copper oxide on the tubing inner surface; however, the presence of $\mathrm{CO}_{2}$ in the water causes carbonic acid $\left(\mathrm{H}_{2} \mathrm{CO}_{3}\right)$ to form. This dissociates into $\mathrm{HCO}_{3}$-and hydrogen ion $\left(\mathrm{H}^{+}\right)$. The $\mathrm{H}^{+}$is attracted to the oxygen in the copper oxide and it forms water. The copper surface is thus left in an ionic form and dissolves. The copper surface is now left unprotected by the copper oxide, so the oxide forms and the process starts all over.

Previously reported work on copper corrosion rates in copper coolant passages $[2,4,5]$ suggest that to minimize copper corrosion, the coolant system should operate between 20 to 50 parts per billion (ppb) dissolved oxygen (DO) content or above $800 \mathrm{ppb}$ DO. The maximum copper corrosion rate occurs at approximately 200-300 ppb DO content. Operating below $10-20 \mathrm{ppb}$ is also not desired because the ultra-low DO content leaves the base metal unprotected and will cause the coolant system's components to be coated with copper [5]. Also, running in the very low DO content range is very difficult to control and it requires costly and bulky auxiliaries. Operating in the 20 to $50 \mathrm{ppb}$ range works well, but it is also difficult to control and drifting up or down in DO content will hasten copper corrosion. The DO content of choice is to operate above $800 \mathrm{ppb}$. This elevated DO content is easy to obtain with an $\mathrm{O}_{2}$ bubbling system in the DI water tank. $\mathrm{CO}_{2}$ can also be easily controlled in the system with a scrubber device using lime or other filter media.

The rate of corrosion in the copper tubing is also influenced by the positive hydrogen ions or the fluid $\mathrm{pH}$. The corrosion rate is minimized at $\mathrm{pH}$ levels above 8.5 [2]. However, higher $\mathrm{pH}$ values (higher alkalinity) contribute to the precipitation of calcium carbonate in the form of scale deposits in the cooling system. These scale deposits can lead to blockages and reduced heat transfer in the coolant system. When the $\mathrm{pH}$ is above 7.0, the copper stays oxidized and the replacement of the oxygen component of the oxide does not occur [2], thus slowing the corrosion process. When the $\mathrm{pH}$ falls below 7.0 the copper ion is stable in solution. The formation of the ion will occur from the oxide state and then be replaced by the oxygen component [2]. The preferred $\mathrm{pH}$ range for the coolant in copper coolant passages is 7 to 8.5 . The $\mathrm{pH}$ or resistivity of DI water coolant systems is commonly maintained by using ion exchange resin filters [2].

Coolant fluid temperature also plays a significant role in the solubility of copper in DI water coolant systems; more so in systems with a $\mathrm{pH}$ range from neutral to acidic (low $\mathrm{pH}$ ). When the $\mathrm{pH}$ is below 7.0, the copper becomes more soluble in the DI water at higher temperatures [2]. This was demonstrated for a DI coolant system with a $\mathrm{pH}$ range from 6.0 to 7.1 and peak temperatures up to $70^{\circ} \mathrm{C}$.

\section{DI WATER COOLANTS VS. FLUORINATED LIQUID}

Other potential coolant fluids were investigated as a possible substitute for DI water or DI-glycol mixture. One alternative coolant fluid that was identified was a highperformance heat transfer fluid from 3M, Novec Engineered Fluid HFE-7500. Novec fluid HFE-7500 is versatile with a wide temperature range, $130^{\circ} \mathrm{C}$ for the boiling point and $-100^{\circ} \mathrm{C}$ for the freezing point. This particular heat-transfer fluid has excellent dielectric properties and is compatible with most metals and hard polymers.

Physical properties of water, water-glycol mixture, and Novec fluid at a room temperature of $25^{\circ} \mathrm{C}$ are listed in Table I. The density of Novec fluid is the highest among these three coolants. A high-density fluid is capable of removing high heat loss and introducing enhanced convection cooling at the expense of a high-pressure drop. The kinematic viscosity of Novec fluid is the lowest, which is good in terms of lowering the pressure drop. However, as shown in table I, both the specific heat and thermal conductivity of the Novec fluid are significantly lower than those of water and water-glycol mixture. For a given coolant flow rate, low specific heat means high coolant temperature rise. Low thermal conductivity implies poor convection heat transfer.

TABLE I. PHYSICAL PROPERTIES OF VARIOUS COOLANTS

\begin{tabular}{|l|c|c|c|c|}
\hline \multicolumn{1}{|c|}{ Coolant } & $\begin{array}{c}\text { Density } \\
\left(\mathbf{k g} / \mathbf{m}^{3}\right)\end{array}$ & $\begin{array}{c}\text { Specific } \\
\text { Heat } \\
(\mathbf{J} / \mathbf{k g} / \mathbf{K})\end{array}$ & $\begin{array}{c}\text { Thermal } \\
\text { Conductivity } \\
(\mathbf{W} / \mathbf{m} / \mathbf{K})\end{array}$ & $\begin{array}{c}\text { Kinematic } \\
\text { Viscosity } \mathbf{~} \\
\left.\mathbf{1 0}^{-7} \mathbf{( m}^{\mathbf{2}} / \mathbf{s}\right)\end{array}$ \\
\hline Water & 997 & 4,181 & 0.608 & 9 \\
\hline $\begin{array}{l}\text { 60\% Water + } \\
\text { 40\% Glycol }\end{array}$ & 1,049 & 3,520 & 0.455 & 23.9 \\
\hline Novec Fluid & 1,610 & 1,128 & 0.065 & 7.7 \\
\hline
\end{tabular}

To compare heat-transfer performance and hydraulic pressure drop in the coolant tubes, cooling parameters of water, water-glycol mixture, and Novec fluid have been calculated under the following conditions.

- $\quad$ Coolant inlet temperature $=25^{\circ} \mathrm{C}$

- $\quad$ Coolant tube inner diameter $=0.165 \mathrm{~cm}$ (0.065 in.)

- $\quad$ Number of coolant tubes $=96$

- Length of each coolant tube $=8 \mathrm{~m}$

- Heat removal rate $=68 \mathrm{~kW}$

The calculated cooling parameters are included in Table II. A coolant flow rate of $15 \mathrm{gpm}$ was chosen because it introduces a flow velocity of $4.6 \mathrm{~m} / \mathrm{s}(15 \mathrm{ft} / \mathrm{s})$, which is the flow velocity well above the industry standard and a flow velocity of interest for several potential applications at UT-CEM. Water is obviously the best heat-transfer fluid and it has the highest convection heat transfer coefficient and the lowest pressure drop. As for the Novec fluid, its temperature rise is twice the temperature rise of water and water-glycol mixture and its convection heat-transfer coefficient is considerably lower than those of water and water-glycol mixture. Even with the Novec flow rate doubled to $30 \mathrm{gpm}$ at the expense of high flow velocity and pressure drop, the heat-transfer performance is still not as good as those of the other two fluids. For a compact cooling system design, which requires a high heat removal rate 
and a compact cooling passage arrangement, Novec fluid does not appear to be a suitable coolant choice.

TABLE II. TABLE 2. COOLING PARAMETERS OF VARIOUS COOLANTS

\begin{tabular}{|l|l|c|c|c|c|}
\hline \multicolumn{1}{|c|}{ Coolant } & $\begin{array}{c}\text { Flow } \\
\text { Rate } \\
(\mathrm{gpm})\end{array}$ & $\begin{array}{c}\text { Temp. } \\
\text { Rise } \\
\left({ }^{\circ} \mathrm{C}\right)\end{array}$ & $\begin{array}{c}\text { Velocity } \\
(\mathrm{m} / \mathrm{s})\end{array}$ & $\begin{array}{c}\text { Heat- } \\
\text { Transfer } \\
\text { Coefficient } \\
\left(\mathrm{W} / \mathrm{m}^{2} / \mathrm{K}\right)\end{array}$ & $\begin{array}{c}\text { Pressure } \\
\text { Drop } \\
(\mathrm{psi})\end{array}$ \\
\hline Water & 15 & 17.2 & 4.6 & 28,510 & 239 \\
\hline $\begin{array}{l}60 \% \text { Water + } \\
\text { 40\%Glycol }\end{array}$ & 15 & 19.5 & 4.6 & 15,870 & 317 \\
\hline Novec Fluid & 15 & 39.5 & 4.6 & 5,796 & 354 \\
\hline Novec Fluid & 30 & 19.7 & 9.2 & 9,393 & 1,282 \\
\hline
\end{tabular}

\section{COOlant Flow Test SetuP}

A schematic of the cooling test setup is shown in Fig. 1. The primary components of the flow loop are the reservoir tank, stainless steel pump, copper coil cooling tubes, particulate filter, and ion resin bed filter. In between components are valves to control flow characteristics and tees for implementing measurement sensors into the flow. Figs. 2 and 3 illustrate the hardware in the coolant flow test system.

The system starts with the 114 li (30 gal) plastic reservoir tank. During operation the tank is filled to $57 \mathrm{li}(15 \mathrm{gal})$. The lid of the reservoir tank has thru holes that connect to an oxygen-feed line and a $\mathrm{CO}_{2}$ absorber to remove $\mathrm{CO}_{2}$ from the air that is in the tank and entering tank. The reservoir tank is situated approximately $0.91 \mathrm{~m}(3 \mathrm{ft})$ above the pump and uses gravity to create an initial pressure head on the pump.

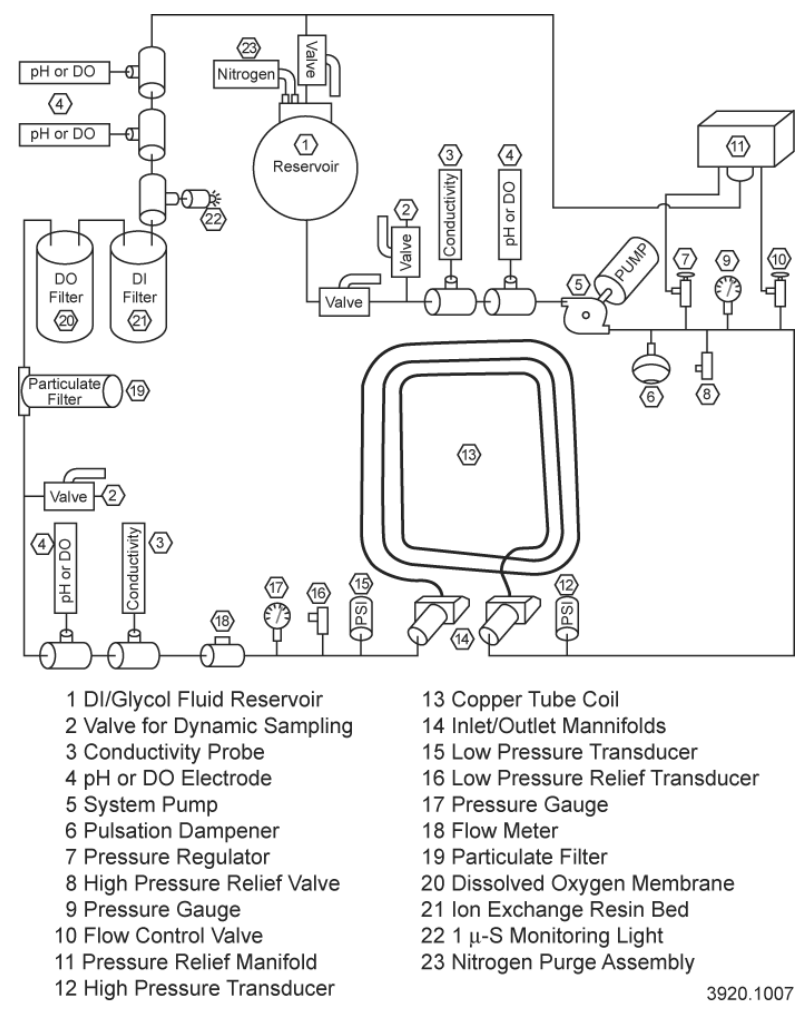

Figure 1. Schematic of coolant flow test setup

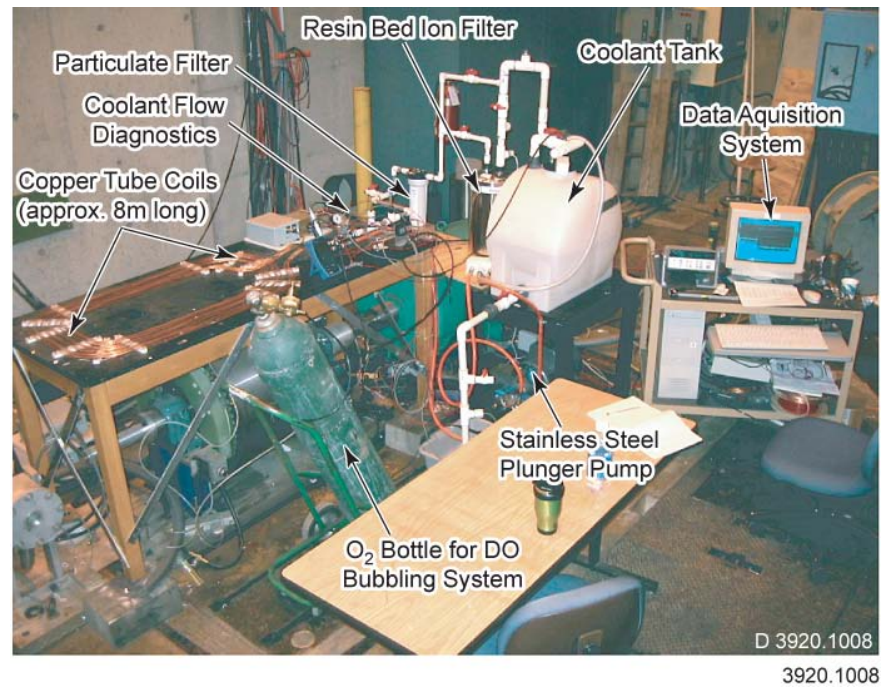

Figure 2. High flow rate coolant test setup

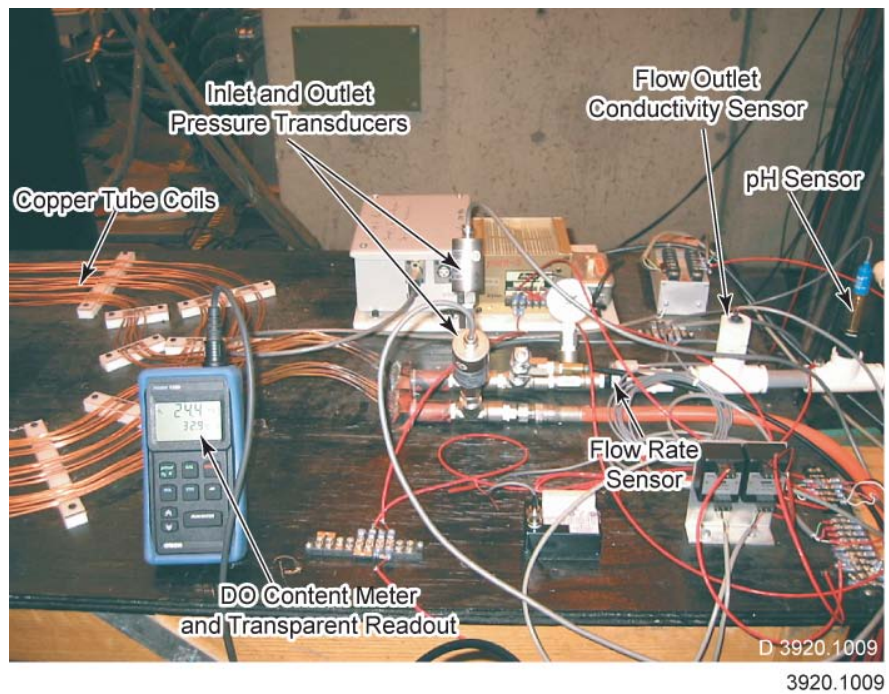

Figure 3. Coolant flow instrumentation on coil inlet and outlet

The pump is a stainless steel plunger pump produced by Cat Pumps (model \#3CP1231) and is driven by a $3 \mathrm{hp} \mathrm{electric}$ motor. The pump produces a flow rate of $2.4 \mathrm{gpm}$ with a pressure range of 0.69 to $13.8 \mathrm{MPa}$ (100 to $2000 \mathrm{psi})$. A stainless steel pulsation dampener and pressure regulator are connected to the backside of the outlet manifold.

A Swagelok® pressure relief valve rated at 5.2 to $10.3 \mathrm{MPa}$ (750 to $1500 \mathrm{psi}$ ) is attached to the front side of the manifold to protect the following components of the high-pressure side of the circuit. A flow-regulating valve adjusts the flow rate into the copper cooling coils after the high-pressure relief valve. Diverted flow from the flow regulating valve and pressure regulator flows into a custom made baffle box through highpressure non-conductive flexible tubing and then returns to the reservoir.

The same non-conductive tubing connects to the copper cooling tube coils. Six copper cooling tubes are laid out in 
parallel to form a cooling coil. The tubes have a measured ID of $0.18 \mathrm{~cm}$ (0.071 in.) and are approximately $8 \mathrm{~m}$ long.

The low-pressure side of the circuit after the copper coils is constructed of $1.27 \mathrm{~cm}$ (0.5 in.) PVC pipe. Another Swagelok ${ }^{\circledR}$ pressure relief valve, rated at 0.34 to $2.4 \mathrm{MPa}$ (50 to $350 \mathrm{psi}$ ), is located after the coils, to protect the low pressure pipes. A standard particulate filter from American Plumber is located after the copper coils. Following this filter is an ion resin bed filter from Culligan ${ }^{\circledR}$ which can be by-passed from the flow. Fluid returns to reservoir.

\section{INSTRUMENTATION AND CALIBRATION}

The primary recorded instrumentation probes located in the cooling test are pressure transducers, flow rate sensor, $\mathrm{pH}$ probe, and conductivity probes. In addition to the recorded instruments, standard Omega pressure gauges are located after the pump and after the copper coils for quick visual readings of pressure. A Thermo-Orion hand held meter, model \#1230, is also used to measure the dissolved oxygen content and temperature of the fluid. This meter is also capable of measuring $\mathrm{pH}$ and conductivity.

The pressure transducers are located directly before and after the cooling tube coils. An Omega PX303 transducer, with a 0 to $13.8 \mathrm{MPa}$ (0 to $2000 \mathrm{psi}$ ) range and 0.5 to $5.5 \mathrm{~V}$ output, is located on the high pressure side of the copper tubes and an Omega PX303 transducer with a 0 to $1.4 \mathrm{MPa}$ (0 to $200 \mathrm{psi}$ ) range is located on the low pressure side. PS series pressure snubbers are placed on the pressure transducers. Both probes were calibrated and verified against a dead weight pressure tester.

Conductivity probe 1 is located before the pump and the second probe is located after the copper coils. The conductivity cells, model \#CS-100, are produced by Pathfinder Instruments and are connected to a CT-1000 transmitter. The probes measure a range of $0-10 \mu \mathrm{S} / \mathrm{cm}$ and the transmitter produces a 4 to $20 \mathrm{~mA}$ output that is measured across a $565 \Omega$ resistor. The probes were calibrated against a $10 \mu \mathrm{S} / \mathrm{cm}$ solution provided by the vendor and were checked against the Thermo Orion hand held conductivity probe.

An epoxy body pH electrode, model \#PHMA pre-amp signal conditioner and \#970070 combination electrode, produced by Sensorex is used in the test. The probe is located after the copper coils, but may be moved later to other locations in the test set up. The probe is connected to a PHMA transmitter that outputs 4 to $20 \mathrm{~mA}$ signal, which is measured across a $500 \Omega$ resistor. The transmitter was calibrated by using a millivolt source to simulate $\mathrm{pH}$ values. The probe and transmitter were then verified against vendor supplied buffer solutions of 4,7 , and $10 \mathrm{pH}$.

An Omega FTB2000 sensor that has a range of 1 to 10 li/min with an output of 55 to $550 \mathrm{~Hz}$ measures the flow rate. The sensor is connected to a FDT frequency to dc converter, which produces an output of $0.5 \mathrm{~mA}$ to $5 \mathrm{~mA}$ measured across a $500 \Omega$ resistor.

All of the recorded sensors are connected to an Agilent 34970A data logger, and data is gathered by the Windows based HP Bench-Link Data Logger software program. During the test, data scans of the sensors are taken every $5 \mathrm{~s}$.

\section{TEST DATA AND OBSERVATIONS}

At the time this paper was written, there had only been five tests run on the coolant flow test setup. These initial five tests were "benchmark" tests to gain experience operating the system and observe some preliminary data for high velocity DI water at several velocities of interest.

Fig. 4 shows data for the first test which was a $1.52 \mathrm{~m} / \mathrm{s}$ (5 $\mathrm{ft} / \mathrm{s}$ ) test for four hours. Fig. 4A shows the fluid $\mathrm{pH}$ conductivity during the test. The $\mathrm{pH}$ was generally around 6.5 with a slight downward slope during the test. Both inlet and outlet fluid conductivities were about $4.5 \times 10^{-7} \mathrm{mho} / \mathrm{cm}(2.22$ x $10^{6} \Omega$-cm resistivity) with a slight upward slope during the test. This corresponds well with the published data that a drop in $\mathrm{pH}$ will cause the fluid to be more conductive. This is seen well in Fig. 4A approximately 1/3 the way into the test. The $\mathrm{pH}$ data shows a pronounced deviation upward with a corresponding drop in the conductivity data. Fig. 4B shows the temperature and DO content during the test. Fig. 4B also plots a calculated flow velocity using the recorded pressure data and the tube diameters.

a)

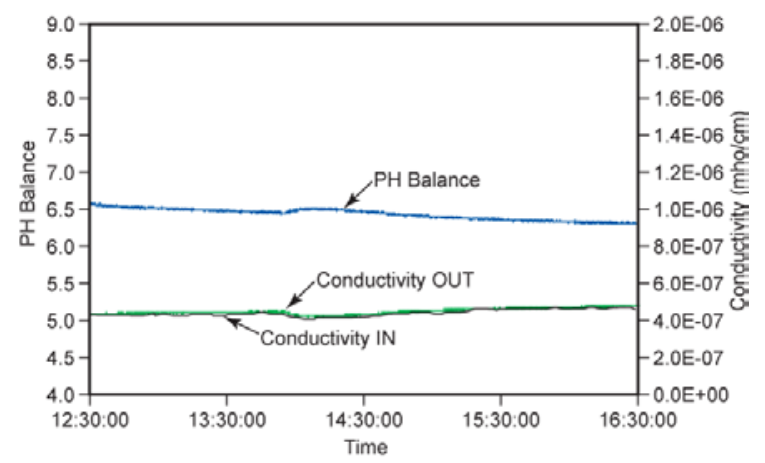

b)

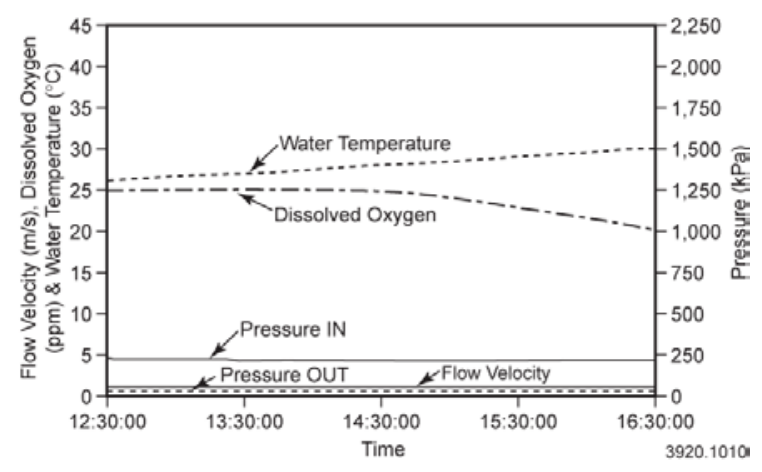

Figure 4. $1.52 \mathrm{~m} / \mathrm{s}$ ( $5 \mathrm{ft} / \mathrm{s}$ ) flow velocity test data - DI water only

Fig. 5 illustrates data for a $10 \mathrm{ft} / \mathrm{s}$ test for four hours. Again the fluid $\mathrm{pH}$ was approximately 6.5 during the duration of the test and the fluid conductivity remained steady at about $3.75 \mathrm{x}$ $10^{-7} \mathrm{mho} / \mathrm{cm}\left(2.67 \times 10^{6} \Omega\right.$-cm) (Fig. 5A). The plotted flow velocity is shown in Fig. $5 \mathrm{~B}$ and it remained a steady $3.0 \mathrm{~m} / \mathrm{s}$ $(10 \mathrm{ft} / \mathrm{s})$ during the test. 
a)

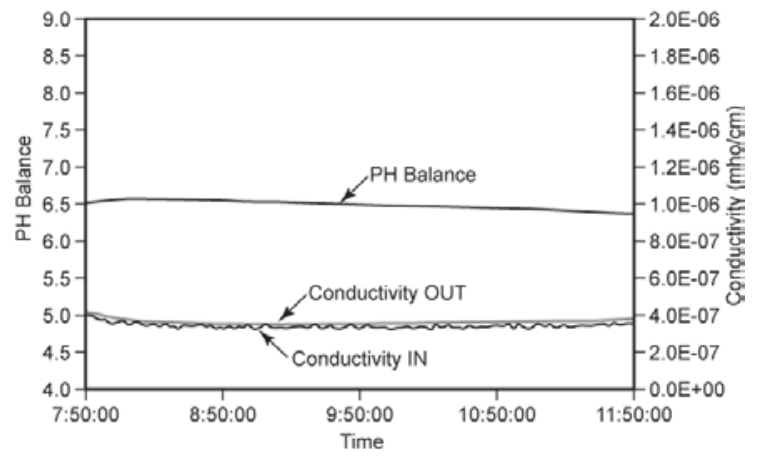

b)

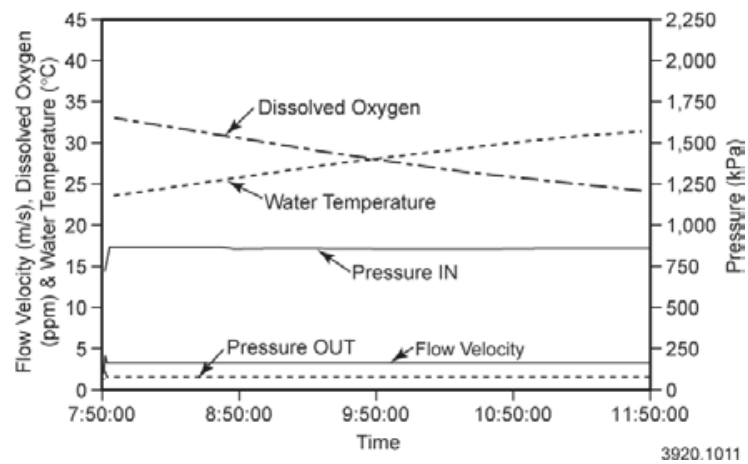

Figure $5 . \quad 3.0 \mathrm{~m} / \mathrm{s}(10 \mathrm{ft} / \mathrm{s})$ flow velocity test data - DI water only

Fig. 6 shows the test data for a $4.6 \mathrm{~m} / \mathrm{s}(15 \mathrm{ft} / \mathrm{s})$ test for four hours with very similar data trends to data from the 1.5 and 3.0 $\mathrm{m} / \mathrm{s}$ (5 and $10 \mathrm{ft} / \mathrm{s}$ ) tests. The conductivity was approximately $3.5 \times 10^{-7} \mathrm{mho} / \mathrm{cm}\left(2.86 \times 10^{6} \Omega-\mathrm{cm}\right)$ with about $6.4 \mathrm{pH}$ (Fig. $6 \mathrm{~A})$. There are some steps in the flow velocity and pressure data in Fig. 6B due to operator pressure adjustments during the test sequence. In Figs. 4B, 5B, and 6B note that the DO content drifts downward during the tests and the fluid temperature drifts upward during the tests. The temperature rise is most likely caused by the plunger pump heating the DI water during the long duration test. It is unclear at this time why the DO content drifts down slightly.

The fourth test was an eight hour test at $4.6 \mathrm{~m} / \mathrm{s}(15 \mathrm{ft} / \mathrm{s})$ without the ion resin bed filter in the fluid circuit. A significant difference is observed in figure 7A. The $\mathrm{pH}$ remains relatively constant at about 6.0 to 6.5 , but the fluid conductivity starts at about $4.0 \times 10^{-7} \mathrm{mho} / \mathrm{cm}\left(2.50 \times 10^{6} \Omega\right.$-cm) and climbs at a constant rate to about $1.6 \times 10^{-6} \mathrm{mho} / \mathrm{cm}\left(0.625 \times 10^{6} \Omega\right.$-cm) at the end of the eight hours. The steady temperature rise is again seen in Fig. 7B with more drastic fluctuations in DO content during this test from operator adjustments.

The next test was a short duration test at $4.6 \mathrm{~m} / \mathrm{s}(15 \mathrm{ft} / \mathrm{s})$ to see how fast the conductivity would recover with the ion resin bed filter back in the circuit. As shown in figure 8A, the conductivity starts at about $1.6 \times 10^{-6} \mathrm{mho} / \mathrm{cm}$ and quickly falls back to approximately $3.0 \times 10^{-7} \mathrm{mho} / \mathrm{cm}$ in only about one to two hours of circulating the fluid through the filter. a)

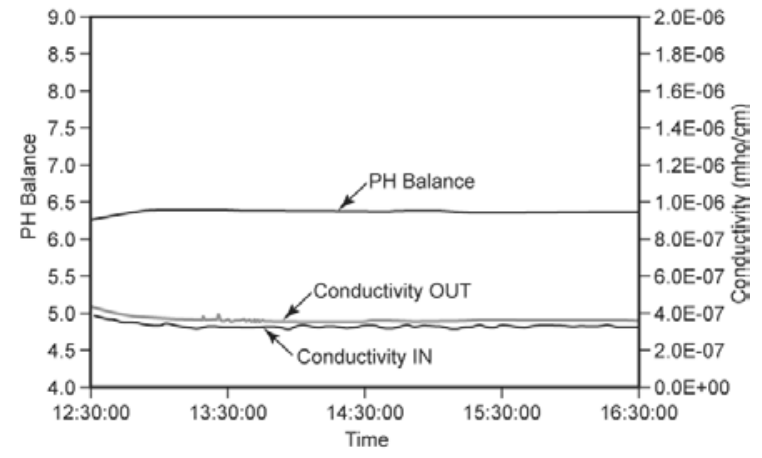

b)

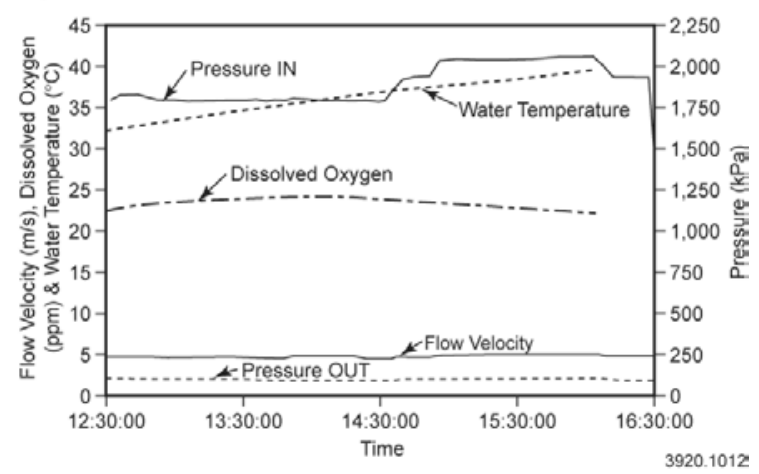

Figure $6.4 .6 \mathrm{~m} / \mathrm{s}(15 \mathrm{ft} / \mathrm{s})$ flow velocity test data - DI water only

a)

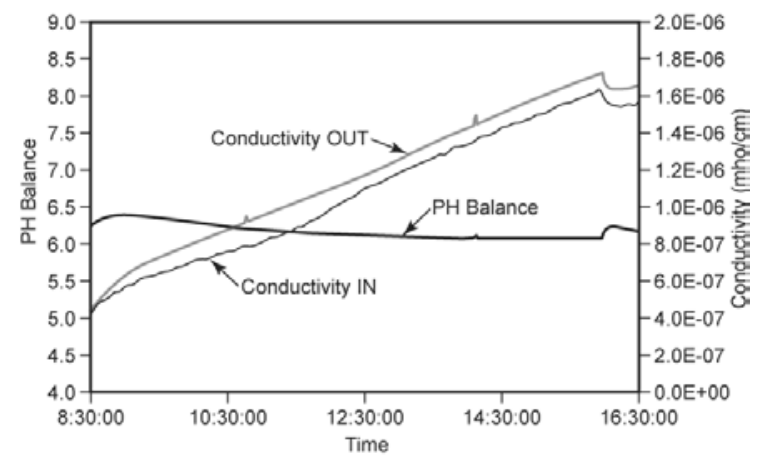

b)

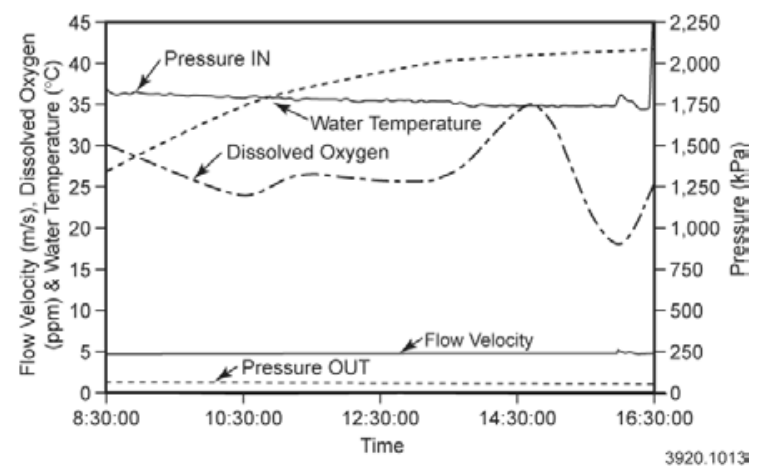

Figure 7. $4.6 \mathrm{~m} / \mathrm{s}(15 \mathrm{ft} / \mathrm{s})$ flow velocity test data - DI water only 
a)

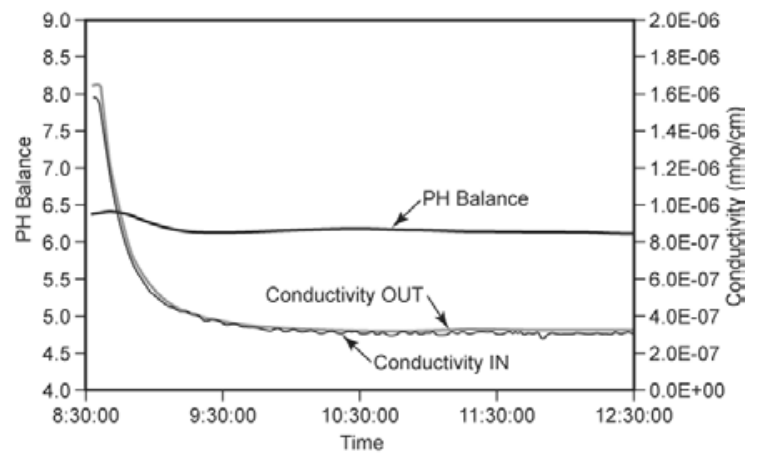

b)

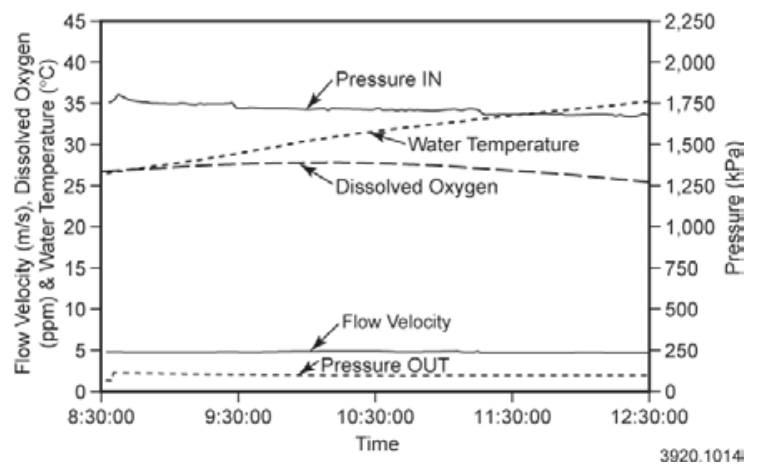

Figure $8 . \quad 4.6 \mathrm{~m} / \mathrm{s}(15 \mathrm{ft} / \mathrm{s})$ flow velocity test data - DI water only

\section{SUMMARY}

UT-CEM has built and operated a high flow velocity coolant test setup to get empirical data on coolant conductivity at high flow velocities. The utility power industry standard is 1.32 to $1.82 \mathrm{~m} / \mathrm{s}$ (5 to $6 \mathrm{ft} / \mathrm{s}$ ), but UT-CEM is interested in flow velocities in copper coolant tubes up to $4.6 \mathrm{~m} / \mathrm{s}(15 \mathrm{ft} / \mathrm{s})$. The test setup has just come on line and the first five tests in the test plan have been conducted and reported on in this paper. Flow velocities ranging from to 1.32 to $4.6 \mathrm{~m} / \mathrm{s}$ ( 5 to $15 \mathrm{ft} / \mathrm{s}$ ) were tested and the fluid conductivity was almost identical over this velocity range when the ion resin bed filter was used. The one test at $4.6 \mathrm{~m} / \mathrm{s}(15 \mathrm{ft} / \mathrm{s})$ without the resin bed filter had a substantial and obvious rise in fluid conductivity. The ion resin bed filter was performing well in removing any copper ions that had eroded or corroded from the inner walls of the copper coolant passages. The fluid resistivity for these first several tests was approximately 2 to $3 \mathrm{M} \Omega$-cm. This resistivity value should be adequate for isolating the coolant system from ground when a short section of non-conducting tubing is used between the machine and the coolant pump.

The follow-on test plan for the coolant test setup will involve tests with DI water and ethylene-glycol mixtures, tests at elevated temperatures, tests with other potential coolant fluids, and perhaps the system will be used to obtain empirical data on the actual wear rate on the inside surface of the copper tubes due to erosion and corrosion.

\section{REFERENCES}

[1] A.M. Gootgeld, "Cooling Water Conditioning \& Quality Control For Tokamaks,” General Atomics, P.O. Box 85608, San Diego, California 92186-9784

[2] R. Dortweg, E.V. Maughan, "The Chemistry of Copper in Water and Related Studies Planned at the Advanced Photon Source," Proceedings of the 2001 Particle Accelerator Conference, Chicago, Illinois, 2001

[3] Scholer, H. and Euteneuer, H., "Corrosion of Copper by Deionized Cooling Water," European Accelerator Conference (EPAC), Rome (June 7-11, 1988)

[4] E.V. Maughan, "The Basics of Stator Coolant Water Chemistry," preseminar workshop presented at the 2000 International Chemistry OnLine Process Instrumentation Workshops in Clearwater, Florida (Nov. 14-17, 2000)

[5] Personal meeting between UT-CEM representatives and Texas Utilities (TXU) technical representatives, May 15, 2003 TXU Energy Plaza, Dallas, Texas 